\title{
Indoor air quality in old and new schools
}

\author{
K. Rumchev, R. Ourangui, D. Bertolatti \& J. Spickett \\ School of Public Health, Curtin University of Technology, Perth, \\ Australia
}

\begin{abstract}
It has been demonstrated that air pollution is associated with a wide variety of health impacts in humans, especially among the elderly and children. In this preliminary study the exposure levels of formaldehyde, particulate matter with a size less than $2.5 \mu \mathrm{m}$ in diameter $\left(\mathrm{PM}_{2.5}\right)$, number of ultra fine particles as well as indoor temperature and relative humidity were measured in six primary schools (three old and three new schools). A total of 20 classrooms were monitored twice a week, at the beginning and at the end of the week. The aim of this study was to compare exposure levels to selected indoor air pollutants between old and new schools located within the Perth metropolitan area, Western Australia. According to the findings the formaldehyde levels were higher than maximum permissible levels recommended by NHMRC in $45 \%$ of samples in old schools and $67 \%$ of the samples in new schools. In regards to $\mathrm{PM}_{2.5}$ concentrations, most samples were lower than the WHO guideline value of $25 \mu \mathrm{g} / \mathrm{m}^{3}$ ( 24 hour exposure). In terms of ultra fine particles, generally old schools had a higher number of ultrafine particles.
\end{abstract}

Keywords: indoor air quality, formaldehyde, particulate matter, school.

\section{Introduction}

Indoor air quality has become a matter of growing global concern over the last thirty years. Recent research indicates that there is a relationship between respiratory disease including asthma and indoor air pollution [1]. Children are generally more susceptible to the effects of air pollution [2] especially particulate pollution [3], because their bodies are growing, and their developmental processes, especially in the lungs, may well be affected by air pollution [1]. Children experience higher exposures to environmental pollutants than adults because, per kg of body weight, they breathe a greater volume of air and ingest 
more material than adults. Children also absorb contaminants more readily. Indoor air quality (IAQ) problems in schools are a significant public health concern. Apart from the home, school is the most important indoor environment for children aged 6-16 in determining pollutant and allergen exposure, as they would spend a significant portion of their lives (about one third or more) in school buildings. Some children may stay in a school setting up to 10 hours per day, at least 1100 hours per year. By the time they finish high school, they would have spent at least 14000 hours breathing the air inside school buildings [2,4]. This may indicate that indoor air quality in schools could have a substantial impact on children's health, thus preventing or reducing exposure to pollutants and allergens in school environment plays an important role in the health of school age children [5].

\section{Methodology}

Environmental monitoring study was conducted in randomly selected government primary schools located within the Perth Metropolitan area. The old schools are defined as those built in the late 1800 s to early 1900 s and the new schools built post 1985. In each school 3 or 4 classrooms were selected and all were used frequently and were occupied most of the day by the same group of students aged between 4 and 8 . All rooms were monitored twice (once at the beginning and once at the end of the week) for 8 hours which would allow detection of any variations through out the day. A total of 20 classrooms were monitored for formaldehyde, particulate matter with size $2.5 \mathrm{mn}$ in diameter $\left(\mathrm{PM}_{2.5}\right)$ and number of ultrafine particles per cubic centimetre. Temperature, relative humidity and air velocity were also measured. Information on heating, air conditioning and ventilation system was collected for each school and studied classrooms. Size and volume of classrooms were also measured and information related to the presence of furniture, materials, fabrics and shelves were collected. All classrooms were also examined for the presence of damp, mould or any unpleasant smell. Information regarding cleaning routines was collected from cleaning staff. Information about ambient temperature and relative humidity was obtained from the Australian Bureau of Meteorology.

\subsection{Indoor air monitoring}

Measurements of formaldehyde were conducted using the passive sampling method described by Levin et al., which utilizes passive diffusers containing acidified 2, 4-dinitrophenylhydrazine (DNPH) followed by analysis using the high-performance liquid chromatography (HPLC) [6].

$\mathrm{PM}_{2.5}$ was measured using the Model 8520 DUST TRAK ${ }^{\mathrm{TM}}$ Aerosol Monitors with $2.5 \mu \mathrm{m}$ inlet conditioner with corresponding impactor plate. Measurements from the DUSTTRAK ${ }^{\mathrm{TM}}$ were recorded as a mass concentration $\left(\mu \mathrm{m} / \mathrm{m}^{3}\right)$.

P-TRAK Ultra fine Particle Counter (UPC) Model 8525 was used to measure the number of ultra fine particles per cubic centimetre (pt/cc). 
Tinytag-ultra Data Logger which is a battery operated device was used to measure indoor temperature and relative humidity for 8 hours periods.

AIR VELOCITY METER MODEL 441M was used to measure air flow through open doors and windows. Kurz Instruments Series 400 is highly accurate instruments for measuring air velocity and static pressure in heating, ventilation, and air-conditioning (HVAC) applications.

AIR FLOW DVA 30VT anemometer was used to measure the air flow through open doors and windows. This instrument is a rotating vane anemometer with digital readout of air velocity.

\section{Statistical consideration}

Statistical analyses were performed with SPSS for Windows, version 14. Transformations were applied when the data did not follow normal distributions. Student t-tests, bivariate correlation and Chi-square test were employed to explore differences and associations between variables. In all statistical analysis, two-tailed tests were used and a 5\% level of significance was applied.

\section{Results}

\subsection{General}

Six primary schools within the Perth Metropolitan area participated in this study.

All classrooms had air conditioning, gas heaters, ceiling fans and a number of natural vents on walls or the ceiling. Old schools had floor boards, mostly carpeted. The floor covering in new schools was a combination of vinyl and carpet ranging from $25 \%$ to $100 \%$ carpeting. However, there was a higher percentage of carpeting in old schools with over $90 \%$ of floor areas were fully carpeted while in new schools just over $70 \%$ of the floors were carpeted.

The results showed that the classrooms in new schools had larger room area than the old schools and the difference was significant $(p<0.01)$. Also, it appeared that old school had bigger black board areas in comparison to new schools $(\mathrm{p}<0.05)$.

\subsection{Indoor air quality in classrooms}

The median concentration of formaldehyde in new schools was $148 \mu \mathrm{g} / \mathrm{m}^{3}$ and was higher than those measured in old schools of $103 \mu \mathrm{g} / \mathrm{m}^{3}$ although the difference was not statistically significant. In old schools $45 \%$ of the samples had higher formaldehyde levels than the maximum permissible level in Australia of $120 \mu \mathrm{g} / \mathrm{m}^{3}$, while in new schools $67 \%$ of the samples were over these levels (Table 1).

In regards to particulate matter, the median concentrations of $\mathrm{PM}_{2.5}$ in both schools were low and didn't exceed the WHO guideline value of $25 \mu \mathrm{g} / \mathrm{m}^{3}$ (24h exposure) (Table 1). Only one classroom from the new and one from the old schools had values higher that $25 \mu \mathrm{g} / \mathrm{m}^{3}$. 
Table 1: $\quad$ Median (range) levels of formaldehyde (HCHO), $\mathrm{PM}_{2.5}, \mathrm{RH}(\%)$ and $\mathrm{T}^{\circ} \mathrm{C}$ for old and new schools.

\begin{tabular}{|c|c|c|c|c|}
\hline & НСНО $\mu \mathrm{g} / \mathrm{m}^{3}$ & $\mathrm{PM}_{2.5} \mu \mathrm{g} / \mathrm{m}^{3}$ & RH (\%) & $\mathrm{T}\left({ }^{\circ} \mathrm{C}\right)$ \\
\hline New & $\begin{array}{c}148.37 \\
(12.92-287.87)\end{array}$ & $\begin{array}{c}10 \\
(4-42)\end{array}$ & $\begin{array}{c}55.0 \\
(38.7-73.5)\end{array}$ & $\begin{array}{c}23.0 \\
(19.95-24.1)\end{array}$ \\
\hline Old & $\begin{array}{c}103.16 \\
(5.67-305)\end{array}$ & $\begin{array}{c}11 \\
(4-37)\end{array}$ & $\begin{array}{c}51.9 \\
(39.4-62.7)\end{array}$ & $\begin{array}{c}19.7 \\
(17-22.1)\end{array}$ \\
\hline p value & 0.302 & 0.164 & 0.634 & 0.000 \\
\hline
\end{tabular}

Table 2: $\quad$ Median (range) levels of formaldehyde (HCHO), $\mathrm{PM}_{2.5}, \mathrm{RH}(\%)$ and $\mathrm{T}^{\circ} \mathrm{C}$ in classrooms with open and closed windows.

\begin{tabular}{|l|c|c|c|c|c|}
\hline $\begin{array}{l}\text { Windows } \\
\text { and doors }\end{array}$ & $\begin{array}{l}\mathrm{HCHO} \\
\mu \mathrm{g} / \mathrm{m}^{3}\end{array}$ & $\begin{array}{c}\mathrm{PM}_{2.5} \\
\mu \mathrm{g} / \mathrm{m}^{3}\end{array}$ & UFP/cc & $\mathrm{RH}(\%)$ & $\mathrm{T}\left({ }^{\circ} \mathrm{C}\right)$ \\
\hline closed & $\begin{array}{c}108.4 \\
(5.7-213.7)\end{array}$ & $\begin{array}{c}10 \\
(4-22)\end{array}$ & 12945 & $\begin{array}{c}55.0 \\
(38.7-73.5)\end{array}$ & $\begin{array}{c}23.0 \\
(19.95-24.1)\end{array}$ \\
\hline open & $\begin{array}{c}158.3 \\
(9.5-305)\end{array}$ & $\begin{array}{c}14.8 \\
(5-42)\end{array}$ & 14263 & $\begin{array}{c}51.9 \\
(39.4-62.7)\end{array}$ & $\begin{array}{c}19.7 \\
(17-22.1)\end{array}$ \\
\hline p value & 0.04 & 0.05 & 0.44 & 0.35 & 0.80 \\
\hline
\end{tabular}

As can be seen from Table 1, the indoor temperature and relative humidity were higher in new schools when compared with those in old schools and the difference was significant for temperature.

The number of UFP was higher $(14158 / \mathrm{cc})$ in the afternoon when compared to the number recorded in the morning $(11748 / \mathrm{cc})$. Additionally, the number of UFP was higher in old schools $16922 / \mathrm{cc}$ when compared to new schools $12128 / \mathrm{cc}$ and the difference was marginally significant $(\mathrm{p}=0.06)$. This is in agreement with the measured outdoor number of UFP as the number was higher outside the old schools $(22790 / \mathrm{cc})$ when compared with the new schools $(9000 / \mathrm{cc})$. Furthermore, the results show that children were exposed to higher number of UFP at the beginning of the week $(14481 / \mathrm{cc})$ when compared to the end of the week when the number of UFP dropped to $12770 / \mathrm{cc}$.

\subsection{Factors contributing to the concentrations of indoor air pollutants}

In the present study exposure levels of $\mathrm{PM}_{2.5}$ were significantly correlated with the number of UFP $(\mathrm{r}=0.34 ; \mathrm{p}<0.05)$ and also with indoor relative humidity $(\mathrm{r}=0.553 ; \mathrm{p}<0.01)$. Further to this, concentrations of $\mathrm{PM}_{2.5}$, and formaldehyde were significantly increased when windows and doors were open (Table 2). 
Although relative humidity, temperature and number of UFP were also affected by open windows and doors the differences were not significant when compared with rooms with closed windows and doors.

Indoor concentrations of $\mathrm{PM}_{2.5}$ were significantly affected by the size of the blackboard as larger blackboard increased significantly the measured levels of $\mathrm{PM}_{2.5}(\mathrm{p}=0.05)$. It appears that old schools had a significantly $(\mathrm{p}<0.01)$ larger blackboard surface area $\left(4.6 \mathrm{~m}^{2}\right)$ compared to those in new schools $\left(1.6 \mathrm{~m}^{2}\right)$. In addition, significantly $(\mathrm{p}<0.01)$ more classrooms in old schools $(90 \%)$ had carpet compared to $70 \%$ in new schools. However, the presence of carpet in classrooms didn't affect the measured levels of formaldehyde and particulate matter.

There was a significant correlation between formaldehyde levels and the average air exchange rate $(\mathrm{r}=0.310, \mathrm{p}=0.050)$, with air velocity through openings $(\mathrm{r}=0.334, \mathrm{p}=0.035)$.

The median indoor relative humidity in new schools was higher at 55\% (38.773.5) when compared to the old schools at 51.8\% (39.4-62.7). The median indoor temperature was $23^{\circ} \mathrm{C}(19.9-24.1)$ for new schools and $19.7^{\circ} \mathrm{C}(17.0-22.1)$ for old schools with a significant difference $(p=0.000)$. However, both the temperature and relative humidity were within the recommended values suggested by ASHRAE [7].

\section{Discussion}

Indoor air pollution has been identified to be affecting children's health worldwide. Air pollutants usually enter the body through the respiratory tract. Environmental irritants such as formaldehyde have been associated with respiratory symptoms including asthma [8,9].

The current study was carried out in schools as children spend a large portion of their daily life at school where they come in contact with air pollutants through their lungs, eyes and skin. Good air quality in classrooms not only favours children's learning ability but also affects teacher and staff's productivity [10]. Concentrations of particulate matter and formaldehyde were compared between old and new schools located in Perth, Western Australia. Relative humidity, temperature and the number of ultrafine particles were also measured in each classroom. Due to time and resource restrictions, the number of schools which participated in the study was limited which is considered as a limitation of the study and it is acknowledged by the authors.

In order to reduce selection bias, the school locations were chosen within the same distance from the coast, all with a reasonable proximity to each other, with brick structures, containing the same furniture, have similar cleaning agents and routines, and all have similar activities performed as all were government schools. All schools were located away from industry and busy road.

Overall the formaldehyde concentrations measured in the present study were high as the median formaldehyde levels in some classes were higher than 120 $\mu \mathrm{g} / \mathrm{m}^{3}$ in both old and new schools, which is the current National Health and Medical Research Council (NHMRC) recommended guideline value for formaldehyde [11], and higher than the WHO threshold of $100 \mu \mathrm{g} / \mathrm{m}^{3}$ [12]. 
These findings are not consistent with the findings established in the study of Seppänen et al [13] where the formaldehyde levels were below the detection limit of $5 \mu \mathrm{g} / \mathrm{m}^{3}$, and in a study of Lee and Chang [14] where the formaldehyde levels ranged from undetectable to $27 \mu \mathrm{g} / \mathrm{m}^{3}$. In the present study, higher number of new schools $(67 \%)$ had higher concentrations of formaldehyde compared to the old schools (45\%) which is consistent with the findings of Newton [15]. This may be due to a number of factors including the new materials and furniture in the new buildings.

Indoor concentrations of $\mathrm{PM}_{2.5}$ were low as in new schools it ranged between $4-42 \mu \mathrm{g} / \mathrm{m}^{3}$ and in old schools between $4-37 \mu \mathrm{g} / \mathrm{m}^{3}$. These findings are consistent with that reported by Rumchev et al [16].

Guidelines for particulate matter have been undergoing a period of revision, as information regarding potential health impacts at lower levels has emerged. The current USEPA standard for $\mathrm{PM}_{10}(24 \mathrm{hr})$ is set at $150 \mu \mathrm{g} / \mathrm{m}^{3}$, however proposed revisions aim to revoke this standard and replace it with a new standard for particles with size between 2.5 and 10 microns in diameter. WHO have recently updated the guideline values for exposure to $\mathrm{PM}_{2.5}$ as $25 \mu \mathrm{gg} / \mathrm{m}^{3}$ (24-hour mean). In the present study exposure levels of $\mathrm{PM}_{2.5}$ did not exceed the WHO guideline value of $25 \mu \mathrm{gg} / \mathrm{m}^{3}$.

In regards to the number of ultrafine particles, when comparing old and new schools, there was no significant difference in morning or afternoon measurements. The number of UFP measured in classrooms was similar to those found in a study by Rumchev et al [16].

There was a positive correlation between indoor and outdoor ultra-fine particles for both morning and afternoon measured levels $(r=0.000, p=0.000)$. This may indicate that number of ultra fine particles outdoors strongly influence the number of those fine particles indoors.

The median indoor relative humidity in new schools was higher of $55 \%$ (38.7-73.5) when compared to those in old schools of 51.8\% (39.4-62.7). Indoor temperatures suggested by ASHRAE [7] should be $19-23^{\circ} \mathrm{C}$ in winter. The median indoor temperature was $23^{\circ} \mathrm{C}(19.9-24.1)$ for new schools and $19.7^{\circ} \mathrm{C}$ (17.0-22.1) for old schools with a significant difference $(\mathrm{p}=0.000)$. The temperatures in the monitored classrooms were within the recommended temperatures.

Some studies determined that improved ventilation rate above $10 \mathrm{Ls}^{-1}$ per person, and up to approximately $20 \mathrm{Ls}^{-1}$ per person, were associated with significant improvements in perceived air quality [17]. In this study the exchange rate was more than adequate in both schools. The ventilation rate was more than $700 \mathrm{Ls}^{-1}$ per person in old schools and over $3000 \mathrm{Ls}^{-1}$ per person in new schools.

\section{Conclusion and recommendations}

In our daily lives we are exposed to various chemicals, some of which are suspected to pose significant health risks. A quantitative evaluation of risk is considered to be essential for developing rational methods for managing environmental chemicals. Investigation of air quality in classrooms helps us to 
characterise pollutant levels and implement corrective measures to improve air quality as required. The most efficient strategy to maintain indoor air quality is to remove the source of contamination or to minimise the levels of air pollutants which can be achieved by good ventilation.

A follow up study is recommended to be carried out in winter and summer when mechanical ventilation is in use to identify any differences between old and new buildings.

\section{References}

[1] CARB (California Air Resources Board): California office of environmental health hazard assessment 2000, Particulate matter and sulphate: evaluation of current California air quality standards with respect to protection of children, by G.D. Thurston, Nelson Institute of Environmental Medicine, Tuxedo.

[2] Kumar, R. \& Eng, P. 1999, 'Indoor air quality solutions for school buildings', Indoor Air, vol. 2, pp. 590-595.

[3] Pope-III, C.A. 2000, 'Epidemiology of fine particulate air pollution and human health: biologic mechanisms and who's at risk?', Environmental Health Perspectives, vol. 108, pp. 713-723.

[4] Leickly, F.E. 2003, 'Children, their school environment, and asthma', Annals of Allergy, Asthma and Immunology, vol. 90, no. 1, pp. 3-5.

[5] Zhang, G., Spickett, J., Rumchev, K., Lee, A.H. \& Stick, S. 2004, 'A low allergen school has improved indoor environmental quality in classrooms', School of Public Health, Curtin University of Technology, Perth.

[6] Levin, J.-O., Andersson, K., Lindahl, R. \& Nilsson, C.A. 1985, 'Determination of sub-part-per-million levels of formaldehyde in air using active or passive sampling on 2,4-dinitrophenylhydrazine-coated glass fiber filters and high performance liquid chromatography', Analytical Chemistry, vol. 57, pp. 1032-1035.

[7] ASHRAE (American Society of Heating, Refrigerating and Air Conditioning Engineers) 1989, ASHRAE Standard 62-1989: Ventilation for Acceptable Indoor Air Quality, Atlanta.

[8] Rumchev, K.B., Spickett, J.T., Bulsara, M.K., Phillips, M.R. \& Stick, S.M. 2002, 'Domestic exposure to formaldehyde significantly increases the risk of asthma in young children', European Respiratory Journal, vol. 20, no. 2, pp. 403-408.

[9] Rumchev, K., Spickett, J., Bulsara, M., Phillips, M. \& Stick, S. 2004, 'Association of domestic exposure to volatile organic compounds with asthma in young children', Thorax, vol. 59, pp. 746-751.

[10] US EPA (United States Environmental Protection Agency) 1996, Indoor air quality basics for schools, U.S. Environmental Protection Agency.

[11] NHMRC (National Health \& Medical Research Council) 1995, Interim national indoor air quality goals, the $115^{\text {th }}$ NHMRC Session, Australian Department of Health and Aged Care. 
[12] WHO (World Health Organisation) 1999, 'Air Quality Guidelines'.

[13] Seppänen, O.A., Fisk, W.J. \& Mendell, M.J. 1999, 'Ventilation Rates and $\mathrm{CO}_{2}$ Concentrations with Health and Other Responses in Commercial and Institutional Buildings', Indoor Air, vol. 9, no. 4, p. 226.

[14] Lee, S.C. \& Chang, M. 2000, 'Indoor and outdoor air quality investigation at schools in Hong Kong', Chemosphere, vol. 41, no. 1-2, pp. 109-113.

[15] Newton, P.W. 2001, Human Settlements, Theme Report: Australia State of the Environment Report, CSIRO Publishing on behalf of the Department of the Environment and Heritage, Commonwealth of Australia.

[16] Rumchev, K., van den Broeck, V. \& Spickett, J. 2003, 'Indoor air quality in university laboratories', Environmental Health, vol. 3, no. 3, pp. 11-19. 